Original Article

\title{
PROPHYLACTIC ANTIBIOTICS IN CAESAREAN DELIVERIES IN A TERITIARY CARE TEACHING HOSPITAL
}

\author{
RAJASREE GADDE ${ }^{1}$, SAJANA GOGINENI ${ }^{2}$, KANCHARLA CHANDANA SRI ${ }^{1}$, JIRRA INDRAJA ${ }^{1}$, MARADANI BRAHMI' \\ VIJAYA KUMAR GHANTA ${ }^{1}$, VISWA SRUJANI KANAGALA ${ }^{1}$
}

1Department of Pharmacy Practice, KVSR Siddhartha College of Pharmaceutical Sciences, Vijayawada, Andhra Pradesh, India, ${ }^{2}$ Department of Obstetrics and Gynaecology, Dr. Pinnamaneni Siddhartha Institute of Medical Sciences and Research Foundation, Chinoutpalli, Gannavaram, Krishna District, Andhra Pradesh, India

Email: kvsrujani@gmail.com

Received: 15 Sep 2020, Revised and Accepted: 17 Nov 2020

ABSTRACT

Objective: Prophylactic antibiotics are used to prevent post-operative infections after Caesarean Section. Studies have suggested a significant role in the timing of prophylaxis. The aim of the study was to evaluate the pattern of antibiotics used and to identify the frequency of post-operative infections in patients undergoing Caesarean Section.

Methods: A prospective observational study was carried out for 6 mo. A total of 120 patients who met the inclusion criteria were recruited into the study. Data collection form was prepared using NICE guidelines. A total of 120 medical records were analysed.

Results: The results revealed that out of 120 study subjects, prophylactic antibiotics Cefotaxime, Metronidazole and Cefixime were used in 119 (99.17\%).

Conclusion: This study concludes that giving prophylactic antibiotics before skin incision reduces risk of post-operative infections in women undergoing Caesarean Section. As the patients did not produce any infections post-surgery $3^{\text {rd }}$ generation Cephalosporins along with Nitroimidazoles can be considered as an effective prophylactic therapy for use during caesarean sections.

Keywords: Caesarean section, Prophylactic antibiotics, Pregnant women, Cephalosporins, Nitro-imidazoles, Post-operative infectious complications (c) 2021 The Authors. Published by Innovare Academic Sciences Pvt Ltd. This is an open access article under the CC BY license (https://creativecommons.org/licenses/by/4.0/) DOI: https://dx.doi.org/10.22159/ijcpr.2021v13i1.40817. Journal homepage: https://innovareacademics.in/journals/index.php/ijcpr

\section{INTRODUCTION}

A Caesarean Section is one of the most common surgical procedures performed in medical practice in obstetrics and gynaecology worldwide [1]. It is indicated when delivery cannot be performed vaginally because it will endanger the mother or foetus [2]

Infectious complications following Caesarean delivery are a common and important cause of maternal morbidity and are related to significantly increased hospital stay. Such issues include diarrhoea, infections with the wound, bacteraemia, Urinary Tract Infections and thrombophlebitis with the pelvic septum [3].

The major goal of antibiotic prophylaxis is to prevent surgical site infection. Antibiotic prophylaxis is needed to prevent infectious symptoms, preserve health and prevent the spread of disease. The development of clinical infection is focused on the complex balance between the host defence mechanism and the factors that influence bacterial virulence. The drugs majorly used in antibiotic prophylaxis are Cephalosporins. Metronidazole also has an indication for prophylaxis against post-operative infections. Mandatory drug level monitoring is not implied for Cephalosporins which is beneficial and also its toxic side effects are unusual [4].

Ideally a drug regimen for antibiotic prophylaxis-

1) Should be well tolerated, fast in response to the majority of pathogens and attain sufficient serum and tissue levels during the procedure.

2) Should not be associated with the development of antimicrobial resistance but at the same time, it has to be inexpensive [5].

Worldwide, Post Caesarean Section infections may lead to significant patient morbidity and can increase health care costs.

American Congress of Obstetrician and Gynaecologists (ACOG) and Canadian society of laboratory technicians and gynecologists recommend that, based on a meta-analysis, antibiotic prophylaxis prior to skin incision compared to cord clamping reduced postpartum prophylaxis and should be administered within 60 min prior to the initiation of Caesarean delivery [6].

\section{MATERIALS AND METHODS}

This is a prospective observational study and a sample of 120 patients who met the inclusion criteria were recruited. This study was conducted over a period of 6 Mo form November 2018-April 2019 at Dr. Pinnamaneni Siddhartha Institute of Medical Sciences and Research Foundation, a tertiary care teaching hospital located at chinnoutpally, Gannavaram Mandal, Krishna district, Andhra Pradesh, India. Initially, a study protocol was presented before the IEC of Dr. PSIMS andRF and approval was obtained. All the women who underwent Caesarean Section in the age group of 19-40 y were included in this study.

Patients who were not willing to participate, who were already on antibiotic therapy for any infection, whose data was found to be insufficient, patients on long-term steroids, immune suppressants and patients with co-morbid conditions like diabetes mellitus, tuberculosis and autoimmune disease were excluded.

The data collection form was intended for collecting-

1. Patient demographic details, obstetric history, prophylactic antibiotics prescribed and their dose, dosage form, duration, timing of administration along with the route of administration.

2. Essential pre-operative laboratory profiles like Haemoglobin, Bleeding Time, Clotting Time, time difference between starting an antibiotic and incision (minutes).

3. And intra operative events like the type of anesthesia, intraoperative complications, type of abdominal incision, duration of surgery, suture material used for skin closure, length of hospital stay. 
Patients were followed up till discharge to identify the postoperative infections.

\section{RESULTS}

\section{Demographic variables}

Higher numbers of Caesarean Sections were observed in the age group 22-25, $51.6 \%$ of total sample population. Rest all were equally distributed (24.2\%) among the age group 18-21 and those who were above 25 y of age. Pregnant women who had a minimum qualification of $10^{\text {th }}(55 \%)$ were considered to be educated. $89.17 \%$ of the subjects were found to be homemakers (table 1).

\section{Co-morbidities}

$88.33 \%$ of the study subjects who underwent Caesarean Section had no co-morbidities. Co-morbidities that were observed in our study include Hypertension (5\%), Hypothyroidism and Bronchial asthma (2.50\%) and Gestational Diabetes Mellitus (1.66\%) (table 2).

\section{Previous caesarean section}

This is the first Caesarean Section delivery for $51.67 \%$ of the subjects. Pregnant women who have undergone at least one Caesarean Section delivery previously were $46.67 \%$ and two Caesarean Section deliveries were $1.67 \%$ of the entire sample population (table 3).

\section{Period of gestation}

82.5\% of the Caesarean Section deliveries were performed between 37-39 w of gestational age. Around $4.2 \%$ of the study subjects underwent Caesarean Section post-full-term gestational age (Above $39 \mathrm{w}$ ) and $13.3 \%$ before $37 \mathrm{w}$ (table 4 ).

\section{Indication for current caesarean section}

It was an Elective Caesarean Section for $67.5 \%$ of the study subjects. Emergency Caesarean Section was indicated for the remaining $32.5 \%$ (table 5).

\section{Prophylactic antibiotic combinations prescribed}

Cefotaxime, along with Metronidazole and Cefixime, was the most commonly used prophylactic Antibiotic combination i.e., $99.17 \%$ of the pregnant women who underwent Caesarean Section were administered with this (table 6).

\section{Intraoperative complications}

$78.33 \%$ of the cases had no-intraoperative complications. Complications experienced for remaining cases were difficult abdominal entry $(10 \%)$ and difficult delivery of the baby (11.67\%) (table 7).

\section{Lengths of hospital stay}

The study subjects who underwent Caesarean Section and had hospital stay duration of $7 \mathrm{~d}$ were greater in proportion $(57.50 \%)$ than those who had hospital stay length above one week (42.50\%) (table 8).

Table 1: Demographic variables

\begin{tabular}{llc}
\hline & Frequency & Percentage \\
\hline Age & & $24.2 \%$ \\
$18-21$ & 29 & $51.6 \%$ \\
$22-25$ & 65 & $24.2 \%$ \\
Above 25 & 29 & $55.0 \%$ \\
Education & & $45.0 \%$ \\
Educated & 66 & $59 \%$ \\
Uneducated & 54 & $8.17 \%$ \\
Occupation & 107 & $10.83 \%$ \\
House wife & 13 & $100.0 \%$ \\
Working women & 120 & \\
Total & & \\
\hline
\end{tabular}

Table 2: Frequency distribution of co-morbidities

\begin{tabular}{lll}
\hline Co-morbidities & Frequency & Percentage \\
\hline Bronchial asthma & 3 & $2.50 \%$ \\
Gestational diabetes mellitus & 2 & $1.66 \%$ \\
Hypertension & 6 & $5 \%$ \\
Hypothyroidism & 3 & $2.50 \%$ \\
No co-morbidities & 106 & $88.33 \%$ \\
Total & 120 & $100.0 \%$ \\
\hline
\end{tabular}

Table 3: Frequency distribution of number of previous CS

\begin{tabular}{lll}
\hline Number of previous sections & Frequency & Percentage \\
\hline 0 & 62 & $51.67 \%$ \\
1 & 56 & $46.67 \%$ \\
2 & $1.67 \%$ & 2 \\
Total & 120 & $100.0 \%$ \\
\hline
\end{tabular}

Table 4: Frequency distribution of period of gestation

\begin{tabular}{lll}
\hline Period of gestation & Frequency & Percentage \\
\hline Below $37 \mathrm{w}$ & 16 & $13.3 \%$ \\
$37-39 \mathrm{w}$ & 99 & $82.5 \%$ \\
Above $39 \mathrm{w}$ & 5 & $4.2 \%$ \\
Total & 120 & $100.0 \%$ \\
\hline
\end{tabular}


Table 5: Frequency distribution of indication for current caesarean section

\begin{tabular}{lll}
\hline Indication for current caesarean section & Frequency & Percentage \\
\hline Elective C-section & 81 & $67.5 \%$ \\
Emergency C-section & 39 & $32.5 \%$ \\
Total & 120 & $100.0 \%$ \\
\hline
\end{tabular}

Table 6: Frequency distribution of prophylactic antibiotics prescribed

\begin{tabular}{lll}
\hline Prophylactic antibiotics prescribed & Frequency & Percentage \\
\hline cefotaxime+metronidazole+Cefixime & $99.17 \%$ \\
cefotaxime+metronidazole+cefixime+Ceftriaxone & 119 & 1 \\
Total & $0.83 \%$ & 120 \\
\hline
\end{tabular}

Table 7: Frequency distribution of intraoperative complications

\begin{tabular}{lll}
\hline Intra-operative complications & Frequency & Percentage \\
\hline Difficult abdominal entry & 12 & $10.00 \%$ \\
Difficult delivery of the baby & 14 & $11.67 \%$ \\
None & 94 & $78.33 \%$ \\
Total & 120 & $100.00 \%$ \\
\hline
\end{tabular}

Table 8: Frequency distribution of length of hospital stay

\begin{tabular}{lll}
\hline Length of hospital stay & Frequency & Percentage \\
\hline 7 D & 69 & $57.50 \%$ \\
Above one week & 51 & $42.50 \%$ \\
Total & 120 & $100.00 \%$ \\
\hline
\end{tabular}

\section{DISCUSSION}

The primary aim of prophylactic antibiotics is to reduce infection and thereby reduce morbidity and mortality. Antibiotic prophylaxis for Caesarean Sections should be perioperative ensuring a high plasma concentration of antibiotic during the surgery. Various studies in obstetric cases proved that there is a definite role of prophylactic antibiotics. Many antibiotics are used in various combinations of single dose or multiple-dose regimens given preoperatively or over the course of several days. Many studies showed that proper and timely administered prophylactic antibiotics can prevent post-operative infection. Wound infection is an important postoperative complication that is associated with readmission in hospital, intervention, prolonged hospital stays and significant clinical and economic consequences.

Prophylactic antibiotics were prescribed in the cases of Caesarean Section delivery in our study. Almost all patients were prescribed with third-generation Cephalosporins like Ceftriaxone and Cefotaxime intravenously which were later converted to oral therapy with Cefixime. A prophylactic antibiotic study conducted by Tippawan et al. reported Ampicillin as the main antibiotic prescribed for Caesarean Section, which belongs to the category of Penicillins [7].

Though prophylactic antibiotics are commonly used for patients who had undergone caesarean section there was a wide variation in the time of administration, type of antibiotic, number of doses and indication for the prescription. In this study most of the women were prescribed with antibiotics half an hour prior to Caesarean Section. Similarly, in a study conducted by Z Shah et al. all patients received antibiotics half hour before surgery and those in multiple doses received additional doses postoperatively. Accordingly, a considerable variation was observed in the timing of antibiotics [8]. A systematic review conducted by Hopkins et al. concluded that a single dose of Ampicillin or $1^{\text {st }}$ generation of Cephalosporins has been established to be as efficacious as the other extended broadspectrum antibiotics [9].

In our study majority of subjects belong to the age group 22-25 and very few cases are from the age groups $18-21$ and above 25 . Comorbidities like Bronchial asthma, Hypothyroidism, and Gestational diabetes were observed in some patients and about $88.33 \%$ of the study population do not have any co-morbid conditions.

The major indications for caesarean section in our study were previous CS (45\%) and breech presentation (22.5\%), foetal distress (15\%) and placenta Previa (1.67), which was very rare. A similar study conducted by Raj Kumar Thapa et al. reported Cephalo-pelvic disproportion constituting about $(62.2 \%)$ of the total population as the major indication for caesarean section, followed by a breech presentation $(18.1 \%)$ and foetal distress $(10.1 \%)$. Induction failure to progress and pre-eclampsia were relatively rare [3].

Emergency LSCS was done in $(32.5 \%)$ of all the cases, and the remaining $(67.5 \%)$ underwent an elective LSCS. Al the LSCS were performed under antibiotic prophylaxis to avoid post-operative infections.

Intra-operative complications like difficulty in abdominal entry $(10 \%)$ and difficulty in delivery of the baby $(11.67 \%)$ were seen in the study subjects and almost (78.33\%) of the study didn't show any intra-operative complications.

The length of the hospital stay, usually for Caesarean Section patients, was more than normal delivery patients in our study. (57.50\%) of women stayed for $1 \mathrm{w}$ whereas (42.5\%) stayed above one week.

Our study shows that third-generation Cephalosporins like Cefixime, Cefotaxime, Ceftriaxone in combination with nitro-imidazole antibiotics Metronidazole are very effective in treating/preventing infections in the case of a Caesarean Section delivery as the study subjects did not develop any infections post-surgery.

\section{CONCLUSION}

Post-operative infections in obstetric and gynaecological settings have been higher as compared to other specialties. Moreover there is great variation in use of antibiotics prophylaxis during Caesarean delivery. Hence, we conclude that the use of pre-Caesarean broadspectrum antibiotics like Cephalosporins and nitro-imidazoles can be recommended to reduce the rates of post-operative complications like surgical site wound infections, febrile morbidity and urinary tract infections and the length of hospital stay that in turn increases the quality of patient care. 


\section{ACKNOWLEDGEMENT}

We thank our Principal, Prof. G. Devala Rao for his constant support. We would like to express our sincere gratitude to Siddhartha Academy of General and Technical Education (SAGTE) for providing all the necessary facilities and the Institutional Ethics Committee of Dr. Pinnamaneni Siddhartha Institute of Medical Sciences and Research Foundation for their valuable suggestions and approval for the completion of this work.

\section{FUNDING}

Nil

\section{AUTHORS CONTRIBUTIONS}

All the Authors contributed equally.

\section{CONFLICT OF INTERESTS}

\section{None}

\section{REFERENCES}

1. Lomangisi D Dlamini, Musa Sekikubo, Janat Tumukunde, Charles Kojjo, Davidson Ocen, Agnes Wabule, et al. Antibiotic prophylaxis for caesarean section at a Ugandan hospital. BMC Pregnancy Childbirth 2015;15:1-7.
2. Shamna MS, VK Kalaichelvan, YM Fazil Marickar, Deepu S. Caesarean section and prophylactic antibiotics. IOSR J Pharm Biol Sci 2014;9:51-4.

3. Raj Kumar Thapa, Bishrawa Bhandari, Kapil Adhikari, Pramila Katila, Prativa Baral, Gulam Muhammad Khan. Antibiotic prophylaxis in caesarean section. Int J Public Health Sci 2012;1:1-6.

4. Shamna MS, VK Kalaichelvan, YM Fazil Marickar, R Manavalan, K Kannan, Deepu S. A study on pattern of using prophylactic antibiotics in caesarean section. IOSR J Pharm 2015;5:12-8.

5. Ruby Kumari, Arti Sharma, Sheetal, Pratibha Roy, Anupriya. To study the effectiveness of prophylactic use of cefriaxone (single dose) in caesarean section in low risk patients in a tertiary care center, Moradabad, India. Int J Res Med Sci 2017;5:5278-82.

6. Chuan Zhang, Linglizhang, Xinghui Liu, Li Zhang, Zhiyouzeng, Lin $\mathrm{Li}$, et al. Timing of antibiotic prophylaxis in elective caesarean delivery: a multi-center randomised controlled trail and meta-analysis. PLoS One 2015;10:1-15.

7. Tippawan Liabsuetrakul, Pisake Lumbiganon, Virasakdi. Prophylactic antibiotic prescription for Caesarean Section. Int Soc Quality Health Care 2002;14:503-8.

8. Zeel Shah, NS Kshirsagar, Shikha Shah. Comparison of singledose prophylactic antibiotics versus five days antibiotics in caesarean section. J Evolution Med Dental Sci 2014;3:3123-9.

9. Hopkins L, Smaill F. Antibiotic prophylaxis regimens and drugs for Caesarean Section. Cochrane Database Syst Rev 2000;2:CD001136. 